\title{
Identification of quantitative trait loci for the fatty acid composition in Korean native chicken
}

\author{
Shil Jin', Hee Bok Park², Dongwon Seo', Nu Ri Choi', Prabuddha Manjula', Muhammad Cahyadi', \\ Samooel Jung ${ }^{1}$, Cheorun Jo ${ }^{4}$, and Jun Heon Lee ${ }^{1, *}$
}

\author{
* Corresponding Author: Jun Heon Lee \\ Tel: +82-42-821-5771, Fax: +82-42-825-9754 \\ E-mail: junheon@cnu.ac.kr \\ ${ }^{1}$ Division of Animal \& Dairy Science, Chungnam \\ National University, Daejeon 34134, Korea \\ 2 Subtropical Livestock Research Institute, National \\ Institute of Animal Science, Jeju 63242, Korea \\ ${ }^{3}$ Department of Animal Science, Faculty of Agriculture, \\ Sebelas Maret University, Surakarta 57126, \\ Indonesia \\ ${ }^{4}$ Department of Agricultural Biotechnology, Center \\ for Food and Bioconvergence, and Research Institute \\ of Agriculture and Life Science, Seoul National \\ University, Seoul 08826, Korea \\ ORCID \\ Shil Jin \\ https://orcid.org/0000-0003-1120-3631 \\ Hee Bok Park \\ https://orcid.org/0000-0002-9418-1898 \\ Dongwon Seo \\ https://orcid.org/0000-0003-0548-7068 \\ Nu Ri Choi \\ https://orcid.org/0000-0002-5526-5124 \\ Prabuddha Manjula \\ https://orcid.org/0000-0001-8074-8323 \\ Muhammad Cahyadi \\ https://orcid.org/0000-0003-3300-6479 \\ Samooel Jung \\ https://orcid.org/0000-0002-8116-188X \\ Cheorun Jo \\ https://orcid.org/0000-0003-2109-3798 \\ Jun Heon Lee \\ https://orcid.org/0000-0003-3996-9209
}

Submitted Oct 23, 2017; Revised Dec 8, 2017; Accepted Jan 20, 2018
Objective: Fatty acid composition is one of the most important meat quality traits because it can contribute to functional, sensorial, and nutritional factors. In this study, quantitative trait locus (QTL) analyses for fatty acid composition traits were investigated in thigh and breast meat of Korean native chicken (KNC).

Methods: In total, 18 fatty acid composition traits were investigated from each meat sample using 83 parents, and $595 \mathrm{~F}_{1}$ chicks of 20 week old. Genotype assessment was performed using 171 informative DNA markers on 26 autosomes. The KNC linkage map was constructed by CRI-MAP software, which calculated genetic distances, with map orders between markers. The half-sib and full-sib QTL analyses were performed using GridQTL and SOLAR programs, respectively.

Results: In total, 30 QTLs (12 in the thigh and 18 in the breast meat) were detected by the half-sib analysis and 7 QTLs ( 3 in the thigh and 4 in the breast meat) were identified by the full-sib analysis.

Conclusion: With further verification of the QTL regions using additional markers and positional candidate gene studies, these results can provide valuable information for determining causative mutations affecting the fatty acid composition of KNC meat. Moreover, these findings may aid in the selection of birds with favorable fatty acid composition traits.

Keywords: Fatty Acid Composition; Korean Native Chicken; Quantitative Trait Locus; Candidate Gene

\section{INTRODUCTION}

The conservation of indigenous animals is highly valuable, and can have a positive impact on the revitalization of the domestic livestock industry. One of the reasons is that these animals can be used as genetic resources for the establishment of new animal production in the future. Several countries have invested enormous efforts to preserve and manage their indigenous genetic resources, and the relevant information is registered in the Domestic Animal Diversity Information System (DAD-IS).

According to an Food and Agriculture Organization of the United Nations (UN-FAO), the trend in meat consumption has changed from pork to poultry meat in recent years; poultry meat is recognized as a healthy, lean meat, as well as a cheap and high-quality protein source. Therefore, the poultry meat industry has grown globally at a high rate. Asian countries are leading the world in terms of poultry production; the global poultry meat production in 2016 was an estimated 116,208 million tons, 39,498 million tons of which were produced by Asian countries. Chicken meat has the largest market share in the poultry industry, and the native chicken market has mainly increased in Asian countries such as China, Japan, Taiwan, and Thailand [1-4]. 
In Korea, the consumption of native chicken meat has been also increasing along with the poultry industry. Korean consumers prefer Korean native chicken (KNC) meat because it has a unique taste and texture compared to commercial broiler meat [5]. Fatty acid composition is one of the factors that contributes to meat quality and flavor; various flavor characteristics are generated by volatile fatty acids that are degraded through oxidation during cooking. Therefore, fatty acid composition can directly affect the meat flavor for consumers, and is an important trait for meat production [6]. Moreover, several unsaturated fatty acids have been investigated as taste-active compounds in the meat [7].

To date, various genetic studies have been conducted on the fatty acid composition of meat. Several association studies were performed between candidate genes and fatty acid composition traits, mainly in cattle and pigs. Based on the accession date of September, 2017, 983 quantitative trait loci (QTL) were investigated that were associated with the 'fatty acid content' trait in cattle, and 5,513 QTL regions were associated with the 'fat composition' trait in pigs (Animal QTL Database). However, to our knowledge, except for a limited number of genetic studies, there has been no QTL research on the fatty acid composition of chicken meat. This may be because the meat composition of monogastric animals such as chickens is mainly affected by environmental factors, such as feed, which normally produces more pronounced effects than the genetic effects. In addition, the fat content (\%) of the meat also affects the fatty acid composition, but chicken meat contains lower fat content than other meats [8].

Therefore, this study was conducted to identify QTL regions that affect the fatty acid composition of chicken meat. In addition, the genetic basis of fatty acid composition that affects the unique taste of the KNC meat, including flavor, was investigated in this study.

\section{MATERIALS AND METHODS}

\section{Experimental animals}

In total, $83 \mathrm{~F}_{0}$ (15 sires and 68 dams) and $595 \mathrm{~F}_{1} \mathrm{KNCs}$ were used for this study. They were composed of 68 half-sib families and 15 full-sib families. In order to consist of families, three sires were mated with 14 or 15 dams in each line, and 595 progenies were produced by artificial insemination. All the bird specimens were provided from National Institute of Animal Science (NIAS), Republic of Korea, and raised under the same environmental conditions until 20 weeks of age. The blood samples from each bird were collected for DNA extraction [9]. This animal experiment strictly followed "The Guide for Care and Use of Laboratory Animals" published by the Institutional Animal Care and Use Committee of the NIAS (2012-C-037) in Korea.
Genotype analysis and linkage map construction In total, 171 DNA markers (132 microsatellites and 39 single nucleotide polymorphisms [SNPs]) across the 26 autosomes were used in this study. The microsatellite markers were genotypes using Genetic Analyzer 3130xl (Applied Biosystems, Foster City, CA, USA) and SNP markers were genotyped by polymerase chain reaction-restriction fragment length polymorphism and Fluidigm Genotyping Technology (Fluidigm, South San Francisco, CA, USA). The order of genetic markers and genetic map distances were determined using CRI-MAP software version 2.4 [10]. The total map length of autosomal chromosome was 3,019.3 cM and the average genetic map distance between markers was $17.5 \mathrm{cM}$ [11].

\section{Phenotype analysis}

The thigh and breast meats of each bird were used in this study. Lipid extraction for fatty acid analysis was performed by the Folch method [12]. The fatty acid composition (\%) was analyzed using a gas chromatography (HP 7890A, Agilent Technologies, Wilmington, DE, USA).

\section{Statistical and quantitative trait locus analyses}

Prior to conduct QTL mapping, normal distribution of the phenotype data were validated. If putative outliers were detected, they were excluded based on normality ascertainment using Ryan-Joiner (RJ) method implemented in Minitab software (Minitab, State College, PA, USA). The RJ score $\geq 0.99$ was employed for the ascertainment of normality. Several fatty acid composition related traits showed significant deviation from normality. Therefore, they were transformed with natural logarithm or square root to eliminate their skewness. A general linear model was carried out using the Minitab software (version 14, Minitab Inc., USA) to identify factors affecting phenotypic variation. Estimation of heritabilities and genetic correlations were conducted by ASReml-R package [13].

QTL analysis was performed using two different approaches: half-sib QTL analysis and full-sib QTL analysis. Phenotypic records used for half-sib QTL mapping were pre-adjusted for fixed effects of sex, batch, line, and carcass weight. A halfsib QTL analysis was conducted with GridQTL program using paternal half-sib families [14]. The conditional probability of alternative QTL genotypes of given marker genotypes was computed at 1-cM intervals within and across the half-sib pedigrees. The pre-adjusted phenotypic data of offspring were then regressed onto the probability of QTL genotype to access the significant effect of allele substitution using the following equation:

$$
y_{i j}=m_{i}+a_{i} x_{i j}+e_{i j}
$$

Where, $y_{i j}$ was the phenotypic record of the $j$ th bird, origi- 
nating from the $i$ th sire; $m_{i}$ was the average effect for the $i$ th half-sib family; $a_{i}$ was the allelic substitution effect for a putative QTL within the $i$ th sire; $x_{i j}$ was the conditional probability for $j$ th individual that could transmit a given allele from the $i$ th sire; $e_{i j}$ was the residual. Chromosome-wide significance thresholds (i.e., $1 \%$ for significant threshold, $5 \%$ for suggestive threshold) were established by 1,000 permutations [15].

A variance component QTL mapping was performed with SOLAR program using full-sib families [16]. First, the identicalby-decent (IBD) matrix was computed based on the markers, the genetic linkage map, and the family information at each putative position along the chromosomes. The $\mathrm{Z}$ chromosome was not included for IBD matrix construction. The computed IBD matrix was then used to model a QTL using the following full linear mixed model:

$$
\mathbf{y}=\mathbf{X b}+\mathbf{Z u}+\mathbf{W q}+\mathbf{e}
$$

(Model 2)

Where, $\mathbf{y}$ was a vector of the phenotypic data for fatty acid composition related traits; $\mathbf{b}$ was a vector of fixed effects including sex, line, batch, and carcass weight; $\mathbf{u}$ was a vector of random polygenic effects; $\mathbf{q}$ was a vector of random QTL effect; $\mathbf{e}$ was a vector of residual; The mean and variance for random polygenic effects was defined as: $\mathbf{u} \sim \mathrm{N}\left(0, \mathbf{A} \sigma_{\mathrm{a}}{ }^{2}\right)$, where A was the numerator relationships matrix computed from the resource $\mathrm{F} 1$ pedigree in this study and $\sigma_{\mathrm{a}}{ }^{2}$ was the additive variance component. The mean and variance for additive QTL effects were defined as: $\mathbf{q} \sim \mathrm{N}\left(0, \mathbf{G} \sigma_{\mathrm{q}}{ }^{2}\right)$, where $\mathbf{G}$ was the IBD matrix and $\sigma_{\mathrm{q}}{ }^{2}$ was the QTL effect variance component, e was a vector of residual with a distribution of $\mathrm{N}\left(0, \mathbf{I}_{\mathrm{e}}{ }^{2}\right)$, where I was the identity matrix and $\sigma_{\mathrm{e}}^{2}$ was the residual variance component. $\mathbf{X}, \mathbf{Z}, \mathbf{W}$ were incidence matrices for $\mathbf{b}, \mathbf{u}$, and $\mathbf{q}$, respectively. The reduced linear mixed model used for the null hypothesis was:

$$
\mathbf{y}=\mathbf{X b}+\mathbf{Z u}+\mathbf{e}
$$

(Model 3)

Model 3 used the same variable definitions as in model 2. Likelihood ratio (LR) for a given genomic position was computed by comparing log likelihood of the two models. Under null hypothesis, the LR value asymptotically followed $\mathrm{x}_{\mathrm{df}=1^{-}}^{2}$ distribution. Chromosome-wide significance thresholds (i.e., $1 \%$ for significant threshold, $5 \%$ for suggestive threshold) were established by a numerical method as described previously [17]. Unless otherwise stated, the p-values are nominal. The 1-LOD (logarithm of odds) drop method was employed to estimate the confidence intervals for the identified QTL by half-sib and full-sib QTL analyses [18].

\section{Positional candidate gene analysis}

Positional candidate genes in the significant QTL regions were screened using Ensembl-BioMart (http://asia.ensembl.org).
The candidate genes were selected based on the gene name and previous scholarly literature using National center for Biotechnology Information (NCBI; https://www.ncbi.nlm. nih.gov) and Google Scholar (scholar.google.co.kr) database.

\section{RESULTS AND DISCUSSION}

Heritabilities and correlations among fatty acid traits The results of heritability estimations for the fatty acid composition of the KNC meat are shown in Table 1. The heritabilities of each trait were estimated to be in the range of 0.025 to 0.560 . All estimated values were moderate to high except thighs C18:2 and 20:1 and breast C20:1. The estimation results of genetic and phenotypic correlations between each fatty acid trait are described in Supplementary Table S1. A wide range of correlations were observed between fatty acids; phenotypic

Table 1. Heritability estimates for fatty acid composition of Korean native

\begin{tabular}{|c|c|c|c|c|}
\hline Trait ${ }^{1)}$ & & $\mathrm{V}_{\mathrm{a}}^{2)}$ & $V_{e}^{3)}$ & $h^{2} \pm \mathrm{SE}^{4)}$ \\
\hline \multirow[t]{13}{*}{ Thigh } & $\mathrm{C} 16: 0$ & 1.183 & 2.739 & $0.302 \pm 0.101$ \\
\hline & $C 16: 1^{s}$ & 0.041 & 0.041 & $0.495 \pm 0.117$ \\
\hline & C18:0 & 2.108 & 2.998 & $0.413 \pm 0.112$ \\
\hline & C18:1 & 5.696 & 11.229 & $0.337 \pm 0.103$ \\
\hline & C18:2 & 0.763 & 3.800 & $0.167 \pm 0.078$ \\
\hline & C18:3 & 0.014 & 0.035 & $0.279 \pm 0.102$ \\
\hline & $\mathrm{C} 20: 1^{\mathrm{N}}$ & 0.002 & 0.029 & $0.048 \pm 0.059$ \\
\hline & $C 20: 4^{N}$ & 0.042 & 0.055 & $0.431 \pm 0.113$ \\
\hline & $\mathrm{C} 22: 6^{\mathrm{N}}$ & 0.037 & 0.059 & $0.386 \pm 0.109$ \\
\hline & SFA & 0.762 & 1.600 & $0.323 \pm 0.103$ \\
\hline & MUFA & 8.220 & 14.328 & $0.365 \pm 0.106$ \\
\hline & PUFA & 6.364 & 16.989 & $0.273 \pm 0.097$ \\
\hline & $\mathrm{P} / \mathrm{S}$ ratio & 0.005 & 0.020 & $0.203 \pm 0.087$ \\
\hline \multirow[t]{13}{*}{ Breast } & C16:0 & 0.524 & 1.282 & $0.290 \pm 0.101$ \\
\hline & $\mathrm{C} 16: 1^{\mathrm{s}}$ & 0.028 & 0.035 & $0.448 \pm 0.117$ \\
\hline & C18:0 & 0.800 & 1.164 & $0.408 \pm 0.111$ \\
\hline & C18:1 & 6.684 & 5.249 & $0.560 \pm 0.124$ \\
\hline & C18:2 & 1.423 & 2.872 & $0.331 \pm 0.104$ \\
\hline & $\mathrm{C} 18: 3^{\mathrm{N}}$ & 0.026 & 0.102 & $0.204 \pm 0.106$ \\
\hline & $\mathrm{C} 20: 1^{\mathrm{N}}$ & 0.001 & 0.020 & $0.025 \pm 0.124$ \\
\hline & $C 20: 4^{s}$ & 0.136 & 0.111 & $0.552 \pm 0.123$ \\
\hline & $C 22: 6^{5}$ & 0.015 & 0.014 & $0.510 \pm 0.120$ \\
\hline & SFA & 0.408 & 1.315 & $0.237 \pm 0.091$ \\
\hline & MUFA & 9.159 & 6.674 & $0.579 \pm 0.125$ \\
\hline & PUFA & 6.778 & 11.611 & $0.369 \pm 0.110$ \\
\hline & $\mathrm{P} / \mathrm{S}$ ratio & 0.006 & 0.014 & $0.289 \pm 0.101$ \\
\hline
\end{tabular}
chickens

1) C16:0, palmitic acid; C16:1, palmitoleic acid; C18:0, stearic acid; C18:1, oleic acid; C18:2, linoleic acid; C18:3, linolenic acid; C20:1, eicosenoic acid; C20:4, arachidonic acid; C22:6, docosahexaenoic acid (DHA); SFA, saturated fatty acid; MUFA, mono unsaturated fatty acid; PUFA, poly unsaturated fatty acid; P/S ratio, PUFA/SFA ratio.

${ }^{2)} V_{a}$, additive genetic component.

${ }^{3)} V_{e}$, residual variance component.

${ }^{4)} h^{2} \pm S E$, heritability with standard error.

${ }^{N}$ Natural log transformed data.

${ }^{\text {s }}$ Square root transformed data. 
correlation showed a range of -0.903 to 0.916 , and genotypic correlation showed a range of -0.968 to 0.981 . There were high negative correlations between monounsaturated fatty acid and polyunsaturated fatty acid contents. These negative correlations were also observed in the estimation of genetic and phenotypic correlation results for thigh and breast meats (Table 2).

It is important to know the heritability of each group for each fatty acid trait, and their correlation structures, to enable the selection of desirable animals; meat fatty acid composition has relevance to meat quality. Therefore, the heritability estimation results of this study can be used for further study on the meat quality of $\mathrm{KNC}$, especially its unique flavor and taste. However, further elucidation of the genetic and phenotypic relationships between each fatty acid trait, between saturated and unsaturated fatty acids, and between fatty acids and other carcass traits, is needed. The fatty acid traits are not a single trait; therefore, it is difficult to apply those in real-life breeding programs [8].

\section{Quantitative trait locus analysis results}

Table 3 shows the results of half-sib and full-sib QTL analyses. Using half-sib analysis, 30 QTL regions were identified in the KNC thigh and breast meat, but the 12 QTL regions of thigh meat and 18 regions of breast meat did not match each other. A total of nine QTL regions were detected at a $1 \%$ chromosome-wide significant level ( $\left.\mathrm{p}_{\text {signifcant }}<0.01\right)$; C16:1, C18:3, and C20:1 in the thigh meat and C16:0, C16:1, C18:0, C18:2, C18:3, and C22:6 in the breast meat. In total, 21 other QTL regions were detected using a $5 \%$ chromosome-wide suggestive levels $\left(\mathrm{p}_{\text {suggestive }}<0.05\right)$.

Full-sib QTL analysis identified a total of seven QTL regions in fatty acid composition-related positions. These QTL regions did also not match between the thigh and breast meat. In the GGA2, two QTLs were investigated for breast C16:0 and C22:6, with $5 \%$ chromosome-side suggestive levels $\left(\mathrm{p}_{\text {sugestive }}<0.05\right)$. Chromosome 7 was related to C20:4 in thigh meat $\left(\mathrm{p}_{\text {suggestive }}\right.$ $<0.05)$, and C16:1 ( $\left.\mathrm{p}_{\text {suggestive }}<0.05\right)$ and C18:1 $\left(\mathrm{p}_{\text {significant }}<0.01\right)$ in breast meat, and chromosome 10 had two suggestive QTL regions for $\mathrm{C} 16: 0$ and $\mathrm{C} 18: 0$ in the thigh meat ( $\mathrm{p}_{\text {suggestive }}<0.05$ ).

The overall result shows that in total, 16 autosomes were related with the fatty acid composition of $\mathrm{KNC}$ meat. Chromosome 7 had the largest number of QTLs (5 QTLs), while four QTL regions were investigated in chromosome 2, 3, and 12 , respectively. In chromosome 2 , there were coincident regions which affected breast C16:0 in the half and full-sib analyses. In total, 10 fatty acid traits had significant QTL regions $\left(\mathrm{p}_{\text {significant }}<0.01\right)$ across nine chromosomes.

There were differences in the QTL regions between thigh and breast meat, one of the reason is the level of fat in the meat [8]. Generally, there are differences in the general composition and cholesterol content of each part of the animal, which also affected the results of this study. The reason that the halfsib and full-sib analysis results showed different QTL regions is dependent on which genetic information was used for this study; the half-sib analysis used only maternal genetic information, while the full-sib analysis used information from both parents when the identical-by-descent proportion was calculated [19].

\section{Possible positional candidate genes}

Table 3 also presented positional candidate genes which related the fatty acid composition of this study. These candidate genes were shown to be directly/indirectly involved in lipid and fat metabolism in previous studies. Adiponectin is encoded by the adiponectin, $\mathrm{C} 1 \mathrm{Q}$ and collagen domain containing ( $A D I P O Q$ ) gene, $A D I P O R 2$ (Adiponectin receptor 2) is one of the $A D I P O Q$ binding receptors. Adiponectin is adipocyte-specific protein, which has an important role in insulin resistance; it is currently being studied in obesity, diabetes, and arteriosclerosis research [20]. Lipoprotein aids in the transportation of hydrophobic lipid molecules, and they are classified by density (high-density lipoprotein [HDL], low-density lipoprotein [LDL], intermediate-density lipoprotein, very-lowdensity lipoprotein, and chylomicrons). LDL receptors mediate the endocytosis of cholesterol-rich LDLs. LDL receptor-related

Table 2. Genetic and phenotypic correlations between fatty acid compositions in Korean native chicken meat (above diagonal is genetic correlation and below diagonal is phenotypic correlation results)

\begin{tabular}{|c|c|c|c|c|c|c|c|c|c|}
\hline \multirow{2}{*}{ Trait } & & \multicolumn{4}{|c|}{ Thigh } & \multicolumn{4}{|c|}{ Breast } \\
\hline & & SFA & MUFA & PUFA & $\mathrm{P} / \mathrm{S}$ ratio & SFA & MUFA & PUFA & $\mathrm{P} / \mathrm{S}$ ratio \\
\hline \multirow[t]{4}{*}{ Thigh } & SFA & - & -0.529 & 0.278 & -0.052 & 0.662 & -0.559 & 0.385 & 0.324 \\
\hline & MUFA & -0.183 & - & -0.966 & -0.809 & -0.418 & 0.954 & -0.917 & -0.801 \\
\hline & PUFA & -0.084 & -0.941 & - & 0.931 & 0.304 & -0.907 & 0.929 & 0.82 \\
\hline & P/S ratio & -0.377 & -0.828 & 0.951 & - & 0.049 & -0.768 & 0.915 & 0.841 \\
\hline \multirow[t]{4}{*}{ Breast } & SFA & 0.443 & -0.052 & -0.075 & -0.193 & - & -0.535 & 0.226 & 0.071 \\
\hline & MUFA & -0.148 & 0.874 & -0.839 & -0.738 & -0.151 & - & -0.948 & -0.862 \\
\hline & PUFA & -0.007 & -0.847 & 0.859 & 0.807 & -0.131 & -0.924 & - & 0.941 \\
\hline & $\mathrm{P} / \mathrm{S}$ ratio & -0.105 & -0.752 & 0.8 & 0.784 & -0.445 & -0.813 & 0.944 & - \\
\hline
\end{tabular}

SFA, saturated fatty acid; MUFA, monounsaturated fatty acid; PUFA, polyunsaturated fatty acid; P/S, PUFA/SFA ratio. 
Table 3. Summary of identified quantitative trait loci (QTLS) for fatty acid composition traits in Korean native chicken

\begin{tabular}{|c|c|c|c|c|c|c|c|c|c|c|c|c|c|c|c|}
\hline \multirow{3}{*}{$\begin{array}{l}\text { Trait }^{1)} \\
\text { Thigh }\end{array}$} & \multirow[b]{3}{*}{$\mathrm{C} 16: 0$} & \multicolumn{7}{|c|}{ Half-sib QTL } & \multicolumn{7}{|c|}{ Full-sib QTL } \\
\hline & & \multirow{2}{*}{$\begin{array}{c}\text { GGA } \\
12\end{array}$} & \multirow{2}{*}{$\begin{array}{c}\text { Position } \\
\text { (cM) }\end{array}$} & \multirow{2}{*}{$\begin{array}{c}\text { F-ratio } \\
2.21^{*}\end{array}$} & \multirow{2}{*}{$\begin{array}{c}\text { p-value } \\
0.005\end{array}$} & \multicolumn{2}{|c|}{ Franking marker } & \multirow{2}{*}{$\begin{array}{c}\text { Positional } \\
\text { candidate gene }\end{array}$} & \multirow{2}{*}{$\frac{\text { GGA }}{10}$} & \multirow{2}{*}{$\frac{\text { LOD }}{2.18^{*}}$} & \multirow{2}{*}{$\frac{p \text {-value }}{0.002}$} & \multirow{2}{*}{$\begin{array}{c}\text { Position } \\
\text { (cM) }\end{array}$} & \multicolumn{2}{|c|}{ Flanking marker } & \multirow{2}{*}{$\begin{array}{c}\text { Positional } \\
\text { candidate gene }\end{array}$} \\
\hline & & & & & & LOC100859653 & MCW0332 & & & & & & ADL0158 & ADL0112 & \\
\hline & $C 16: 1^{\mathrm{s}}$ & 3 & 261 & $3.49^{* *}$ & $9.82 \mathrm{E}-06$ & $O D C 4$ & MCW0037 & - & - & - & - & - & - & - & - \\
\hline & $\mathrm{C} 18: 0$ & - & - & - & - & - & - & - & 10 & $1.93^{*}$ & 0.003 & 87 & ADL0158 & ADL0112 & - \\
\hline & C18:2 & 1 & 150 & $2.71^{*}$ & 0.001 & MCW0297 & $C B L B$ & ADIPOR2, LRPG, FAR2 & - & - & - & - & - & - & - \\
\hline & C18:2 & 7 & 52 & $2.08^{*}$ & 0.01 & LEI0064 & ADL0315 & - & - & - & - & - & - & - & - \\
\hline & C18:3 & 9 & 52 & $2.61^{* *}$ & 0.001 & R0S0078 & ADL0259 & $H D L B P, A D I P O Q$ & - & - & - & - & - & - & - \\
\hline & $\mathrm{C} 20: 1^{\mathrm{N}}$ & 2 & 208 & $2.77^{\star *}$ & $3.90 E-04$ & FABP4 & MCW0320 & $F A B P 4, L R P 12$ & - & - & - & - & - & - & - \\
\hline & $\mathrm{C} 20: 1^{\mathrm{N}}$ & 16 & 15 & $2.08^{*}$ & 0.01 & MCW0151 & ADL0293 & - & - & - & - & - & - & - & - \\
\hline & $C 20: 4^{N}$ & 12 & 36 & $2.08^{*}$ & 0.01 & LOC100859653 & MCW0332 & - & 7 & $1.89^{*}$ & 0.003 & 93 & ROS0019 & ADL0169 & MGAT5, LRP1B \\
\hline & C22:6 & 3 & 31 & $2.26^{*}$ & 0.004 & LEI0043 & UGP2 & - & - & - & - & - & - & - & - \\
\hline & C22:6 & 6 & 31 & $2.06^{*}$ & 0.011 & ADL0230 & MCW0176 & - & - & - & - & - & - & - & - \\
\hline & C22:6 & 10 & 86 & $2.11^{*}$ & 0.008 & ADL0158 & ADL0112 & - & - & - & - & - & - & - & - \\
\hline & C22:6 & 24 & 52 & $2.1^{*}$ & 0.009 & NTM & LEI0069 & - & - & - & - & - & - & - & - \\
\hline \multirow[t]{18}{*}{ Breast } & $\mathrm{C} 16: 0$ & 2 & 85 & $2.43^{*}$ & 0.002 & MCW0039 & MCW0087 & GCNT2 & 2 & $2.25^{*}$ & 0.001 & 74 & MCW0039 & ADL0181 & GCNT2 \\
\hline & $\mathrm{C} 16: 0$ & 7 & 87 & $2.11^{*}$ & 0.008 & ROS0019 & MCW0316 & LRP1B & - & - & - & - & - & - & - \\
\hline & $\mathrm{C} 16: 0$ & 8 & 81 & $2.05^{*}$ & 0.011 & MCW0160 & MCW0351 & ELOVL1, LRPB & - & - & - & - & - & - & - \\
\hline & C16:0 & 20 & 21 & $2.24^{* *}$ & 0.005 & LEI0080 & ADL0034 & - & - & - & - & - & - & - & - \\
\hline & $C 16: 1^{5}$ & 3 & 34 & $2.79^{* *}$ & $3.45 \mathrm{E}-04$ & LEIO043 & UGP2 & - & 7 & $1.66^{*}$ & 0.006 & 100 & ADL0315 & ADL0169 & $\angle R P 1 B$ \\
\hline & C18:0 & 20 & 1 & $2.04^{*}$ & 0.012 & LEIO080 & ADL0034 & - & - & - & - & - & - & - & - \\
\hline & $\mathrm{C} 18: 0$ & 22 & 24 & $2.2^{* *}$ & 0.006 & ROS0073 & GCT0042 & - & - & - & - & - & - & - & - \\
\hline & C18:1 & 5 & 180 & $2.25^{*}$ & 0.004 & MCW0081 & ADL0298 & MGAT2 & 7 & $2.54^{* *}$ & 0.001 & 99 & ADL0315 & ADL0169 & - \\
\hline & C18:1 & 24 & 0 & $2.56^{*}$ & 0.001 & $\mathrm{C} 2 \mathrm{CD} 2 \mathrm{~L}$ & FLII & - & - & - & - & - & - & - & - \\
\hline & C18:2 & 1 & 155 & $2.94^{* *}$ & 1.63E-04 & MCW0297 & $C B L B$ & ADIPOR2, LRPG, FAR2 & - & - & - & - & - & - & - \\
\hline & C18:2 & 5 & 0 & $2.14^{*}$ & 0.007 & MCW0263 & MCW0193 & - & - & - & - & - & - & - & - \\
\hline & $\mathrm{C} 18: 3^{\mathrm{N}}$ & 9 & 43 & $2.19^{*}$ & 0.006 & R0S0078 & ADL0021 & $H D L B P, A D I P O Q$ & - & - & - & - & - & - & - \\
\hline & $\mathrm{C} 18: 3^{\mathrm{N}}$ & 12 & 59 & $2.27^{* *}$ & 0.004 & ADLO240 & MCW0332 & - & - & - & - & - & - & - & - \\
\hline & $\mathrm{C} 18: 3^{\mathrm{N}}$ & 15 & 16 & $2.04^{*}$ & 0.012 & ADL0206 & MCW0080 & - & - & - & - & - & - & - & - \\
\hline & $\mathrm{C} 20: 1^{\mathrm{N}}$ & 3 & 162 & $3.19^{*}$ & $1.39 \mathrm{E}-04$ & MCW0127 & SLC35A1 & FABP7 & - & - & - & - & - & - & - \\
\hline & $C 20: 4^{5}$ & 12 & 41 & $2.08^{*}$ & 0.01 & ADL0240 & MCW0332 & - & - & - & - & - & - & - & - \\
\hline & $C 22: 6^{5}$ & 4 & 0 & $2.21^{* *}$ & 0.005 & ADL0255 & ADL0203 & ATP11C & 2 & $1.98^{*}$ & 0.003 & 79 & MCW0039 & MCW0009 & GCNT2 \\
\hline & $C 22: 6^{5}$ & 5 & 0 & $2.14^{*}$ & 0.007 & MCW0263 & MCW0193 & - & - & - & - & - & - & - & - \\
\hline
\end{tabular}

LOD, logarithm of odds; $A D I P O R 2$, adiponectin receptor 2; LRP6, LDL receptor-related proteins 6; FAR2, fatty acyl-CoA reductase 2; HDLBP, HDL-binding protein; $A D I P O Q$, adiponectin, C1Q and collagen domain containing; FABP4, fatty acid binding proteins 4; GCNT2, glucosaminyl (N-Acetyl) transferase 2; ELOVL1, elongation of very long-chain fatty acids proteins 1; MGAT2, mannosyl-glycoprotein $\mathrm{N}$-acetylglucosaminyltransferases 2; ATP11C, ATPase 11C.

1) C16:0, palmitic acid; C16:1, palmitoleic acid; C18:0, stearic acid; C18:1, oleic acid; C18:2, linoleic acid; C18:3, linolenic acid; C20:1, eicosenoic acid; C20:4, arachidonic acid; C22:6 docosahexaenoic acid (DHA).

${ }^{\mathrm{N}}$ Natural log transformed data. ${ }^{\mathrm{S}}$ Square root transformed data.

* $5 \%$ suggestive threshold. ** $1 \%$ significant threshold.

proteins conduct a wide range of physiological processes, including the regulation of lipid metabolism [21]. HDL binding proteins re regulated by the level of cellular cholesterol, and may play a role in protecting cells from the over-accumulation of cholesterol [22]. Fatty acid binding proteins $(F A B P)$ are a family of lipid-binding proteins ( $F A B P 1$ to $F A B P 9$ genes), and are distributed by tissue specificity. Their main role is the regulation of fatty acid uptake and intracellular transport [23]. Elongation of very long-chain fatty acids proteins (ELOVL) encode the enzyme elongase, which catalyzes the fatty acid elongation process. The ELOVL family (ELOVL1 to ELOVL7 genes) have a characteristic fatty acid substrate specificity and tissue-specific gene expression [24,25]. Fatty acyl-CoA reductase $(F A R)$ catalyzes the reduction of fatty acyl-CoA to fatty alcohol, and FAR1 and FAR2 encode the reductase enzyme, which is needed for the first step of the wax biosynthesis. Mannosyl-glycoprotein $\mathrm{N}$-acetylglucosaminyltransferases are a subset of glycosyltransferases, which catalase glucosidic bond formations using sugars that are offered from nucleo- side phosphates or lipid phosphates [26]. Glucosaminyl (NAcetyl) transferase (GCNT) also includes glycosyltransferase, and GCNT2 was reported as a glycosphingolipid biosynthesisrelated gene in chickens [27]. The P-type ATPase catalyzes the translocation of phospholipids of cell membranes. The phospholipid transporting ATPase $11 \mathrm{C}$ is active at the plasma membrane as a major type IV P-ATPase flippase, and transports phosphatidylserine from the outer to inner leaflet of the membrane lipid bilayer of most cells [28].

Based on the role of these candidate genes associated with lipid/fat metabolism, some of the genes have already been reported in beef and pork, in which they were found to affect meat quality traits. As a representative gene, $A D I P O Q$ was found to significantly affect traits such as marbling, back fat thickness, carcass weight, and fatty acid oxidation [29-32]. FABP4 was also found to have an effect on the intramuscular fat composition, marbling, and fatty acid composition [33-36].

Consumers in modern society are increasingly interested in healthy livestock products and high-quality meat. There- 
fore, there is a growing need for genetic studies on the meat fatty acid composition to maintain and improve these qualities. Fatty acid composition is closely related with lipid and fat metabolism, so it is necessary to understand the synthesis process and the genetic relationships between fatty acids and lipids, and between different fatty acids in meat. Research is also needed to thoroughly elucidate the function of the genes within the investigated QTL region that were unknown in this study.

This study provides insights into the fatty acid composition of chicken meat because there is lack of genetic research in this area. The estimation of heritability and the corresponding correlations observed in this study can be used for the genetic improvement of meat fatty acid composition in the future.

Taken together, the results of this study can be provide a baseline for the causative genes that affect the fatty acid composition of chickens, especially regarding meat flavor. Flavor is one of the most important traits that reflects the consumer's preferences in Korea. Moreover, techniques similar to this study are expected to be used for breeding strategies of KNC as well as the production of new commercial chicken breeds using indigenous chickens, in the future.

\section{CONFLICT OF INTEREST}

We certify that there is no conflict of interest with any financial organization regarding the material discussed in the manuscript.

\section{ACKNOWLEDGMENTS}

This work was supported by the Korea Institute of Planning and Evaluation for Technology in Food, Agriculture, Forestry and Fisheries through the Golden Seed Project, Ministry of Agriculture, Food and Rural Affairs (213010-05-2-SB250) and the "Cooperative Research Program for Agriculture Science \& Technology Development (PJ012820052018)" of the Rural Development Administration, Republic of Korea.

\section{REFERENCES}

1. Rikimaru K, Takahashi H. A method for discriminating a Japanese brand of chicken, the Hinai-jidori, using microsatellite markers. Poult Sci 2007;86:1881-6.

2. Tang $\mathrm{H}$, Gong $\mathrm{Y}, \mathrm{Wu} \mathrm{C}$, et al. Variation of meat quality traits among five genotypes of chicken. Poult Sci 2009;88:2212-8.

3. Chumngoen W, Tan F-J. Relationships between descriptive sensory attributes and physicochemical analysis of broiler and Taiwan native chicken breast meat. Asian-Australas J Anim Sci 2015;28:1028-37.

4. Sasaki K, Motoyama M, Tagawa Y, et al. Qualitative and quan- titative comparisons of texture characteristics between broiler and jidori-niku, Japanese indigenous chicken meat, assessed by a trained panel. Nippon Kakin Gakkaishi 2017;54:87-96.

5. Choe J-H, Nam K-C, Jung S, et al. Differences in the quality characteristics between commercial Korean native chickens and broilers. Korean J Food Sci Anim Resour 2010;30:13-9.

6. Jayasena DD, Jung S, Kim HJ, et al. Comparison of quality traits of meat from Korean native chickens and broilers used in two different traditional Korean cuisines. Asian-Australas J Anim Sci 2013;26:1038-46.

7. Jayasena DD, Jung S, Kim HJ, et al. Taste-active compound levels in Korean native chicken meat: The effects of bird age and the cooking process. Poult Sci 2015;94:1964-72.

8. De Smet S, Raes K, Demeyer D. Meat fatty acid composition as affected by fatness and genetic factors: a review. Anim Res 2004;53:81-98.

9. Miller S, Dykes D, Polesky H. A simple salting out procedure for extracting DNA from human nucleated cells. Nucleic Acids Res 1988;16:1215.

10. Green P. Construction and comparison of chromosome 21 radiation hybrid and linkage maps using CRI-MAP. Cytogenet Cell Genet 1992;59:122-4.

11. Jin S, Lee JH, Seo DW, et al. A major locus for quantitatively measured shank skin color traits in Korean native chicken. Asian-Australas J Anim Sci 2016;29:1555-61.

12. Folch J, Lees M, Sloane-Stanley G. A simple method for the isolation and purification of total lipids from animal tissues. J Biol Chem 1957;226:497-509.

13. Wilson AJ, Reale $\mathrm{D}$, Clements $\mathrm{MN}$, et al. An ecologist's guide to the animal model. J Anim Ecol 2010;79:13-26.

14. Seaton G, Hernandez J, Grunchec J-A, et al. GridQTL: a grid portal for QTL mapping of compute intensive datasets. In: Proceedings of the 8th world congress on genetics applied to livestock production; 2006 August 13-18: Belo Horizonte, MG, Brasil.

15. Churchill GA, Doerge RW. Empirical threshold values for quantitative trait mapping. Genetics 1994;138:963-71.

16. Almasy L, Blangero J. Variance component methods for analysis of complex phenotypes. Cold Spring Harb Protoc 2010; 2010:pdb.top77.

17. Piepho H-P. A quick method for computing approximate thresholds for quantitative trait loci detection. Genetics 2001; 157:425-32.

18. Lander ES, Botstein D. Mapping mendelian factors underlying quantitative traits using RFLP linkage maps. Genetics 1989; 121:185-99.

19. Seo D, Park H, Jung S, et al. QTL analyses of general compound, color, and $\mathrm{pH}$ traits in breast and thigh muscles in Korean native chicken. Livest Sci 2015;182:145-50.

20. Lihn A, Pedersen SB, Richelsen B. Adiponectin: action, regulation and association to insulin sensitivity. Obes Rev 2005;6: 13-21. 
21. May P, Woldt E, Matz RL, Boucher P. The LDL receptor-related protein (LRP) family: An old family of proteins with new physiological functions. Ann Med 2007;39:219-28.

22. Cánovas E, Quintanilla R, Badaoui B, et al. Pig HDL-binding protein $(H D L B P)$ genotype is associated with intramuscular fat percentage. Livest Sci 2009;126:298-301.

23. Chmurzyńska A. The multigene family of fatty acid-binding proteins (FABPs): function, structure and polymorphism. J Appl Genet 2006;47:39-48.

24. Brolinson A. Regulation of Elovl and fatty acid metabolism [Doctoral thesis]. Stockholm, Sweden: Stockholm University; 2009.

25. Xue X, Feng CY, Hixson SM, et al. Characterization of the fatty acyl elongase (elovl) gene family, and hepatic elovl and delta- 6 fatty acyl desaturase transcript expression and fatty acid responses to diets containing camelina oil in Atlantic cod (Gadus morhua). Comp Biochem Physiol Part B: Biochem Mol Biol 2014;175:9-22.

26. Lairson L, Henrissat B, Davies G, Withers S. Glycosyltransferases: structures, functions, and mechanisms. Annu Rev Biochem 2008;77:521-55.

27. D'Andre HC, Paul W, Shen X, et al. Identification and characterization of genes that control fat deposition in chickens. J Anim Sci Biotechnol 2013;4:43.

28. Arashiki N, Takakuwa Y, Mohandas N, et al. ATP11C is a major flippase in human erythrocytes and its defect causes congenital hemolytic anemia. Haematologica 2016;101:559-65.

29. Berner HS, Lyngstadaas SP, Spahr A, et al. Adiponectin and its receptors are expressed in bone-forming cells. Bone 2004; 35:842-9.

30. Dall'Olio S, Davoli R, Buttazzoni L, Zambonelli P, Russo V. Study of porcine adiponectin (ADIPOQ) gene and association of a missense mutation with EBVs for production and carcass traits in Italian Duroc heavy pigs. Livest Sci 2009;125:101-4.

31. Shin S, Chung E. Novel SNPs in the bovine ADIPOQ and PPARGC1A genes are associated with carcass traits in Hanwoo (Korean cattle). Mol Biol Rep 2013;40:4651-60.

32. Choi Y, Davis ME, Chung H. Effects of genetic variants in the promoter region of the bovine adiponectin $(A D I P O Q)$ gene on marbling of Hanwoo beef cattle. Meat Sci 2015;105:57-62.

33. Michal J, Zhang Z, Gaskins C, Jiang Z. The bovine fatty acid binding protein 4 gene is significantly associated with marbling and subcutaneous fat depth in Wagyu $\times$ Limousin F2 crosses. Anim Genet 2006;37:400-2.

34. Hoashi S, Hinenoya T, Tanaka A, et al. Association between fatty acid compositions and genotypes of FABP4 and LXRalpha in Japanese Black cattle. BMC Genet 2008;9:84.

35. Barendse W, Bunch R, Thomas M, Harrison B. A splice site single nucleotide polymorphism of the fatty acid binding protein 4 gene appears to be associated with intramuscular fat deposition in longissimus muscle in Australian cattle. Anim Genet 2009;40:770-3.

36. Chen Q-M, Wang H, Zeng Y-Q, Chen W. Developmental changes and effect on intramuscular fat content of $H$-FABP and $A-F A B P$ mRNA expression in pigs. J Appl Genet 2013; 54:119-23. 